\title{
Empirical Analysis on Influencing Factors of Farmers Specialized Production
}

\author{
HU Yi-ting ${ }^{1}$ WANG Dan ${ }^{2}$ \\ 1,2 Economy and Management College, Shihezi University, Shihezi, Xinjiang, China
}

\begin{abstract}
Specialized production is an important choice to increase agricultural efficiency ,promote sustained increase in farmer income, and crack "three rural" issues. With survey data from 882 farmers of 82 counties of 17 provinces, using Logistic regression model, this paper conducts an empirical test on factors affecting the farmers' specialized production. The results show that the farmers' specialized production is affected significantly by the combined effect of multiple factors such as literacy, agricultural training, attitudes toward risk of head of household, and family size, land size, product type, distance to the town and the proportion of migrant workers.
\end{abstract}

Keywords:farmers;specialized production; influencing factors; logistic model

\section{Introduction}

"Three rural" issues of China are mainly reflected in that farmers' overall income level is low, which is rooted in agriculture inefficient. It has a strong relationship with the diversification, small-scale, extensive mode of operation which farmers have utilized for a long time. To change the farmers' current operation mode and guide them to turn to specialized, large-scale and intensive management gradually, which has become an inevitable trend for China's agricultural development. Facts have proved that farmer specialized operation improved the efficiency, increased the income of farmers greatly, promoted the agriculture industrialization and agricultural modernization.

Farmer specialized production is a kind of production activity means farmer specialize in a particular agricultural product or a dominant kind of agricultural production. In the 1980s, domestic scholars had studied specialized production problems of farmers and most of them emphasized on the analysis of the situation of the development of specialized households (Fang , 1985).Then, farmers specialization was discussed sporadically by only a few scholars, and limited to the analysis of theoretical or significance level(Luo\&Chen, 200;Zhou\&Cai,2000), which may mainly be associated with the small scale of our farmers, the low degree of specialization. Since the specialized production is the inevitable choice of the future of Chinese farmers, then which factors are farmers specialized influenced by in the end ?Based on survey data from 882 farmers in 82 counties of 17 provinces in China, the paper analyses the impact factors of farmers specialized production, and provide policy recommendations for the Government to encourage, guide and support the farmers to engage in specialized production.

\section{Theoretical analysis and hypotheses}

From the perspective of Economics, whether farmers choose specialization or not, which is mainly based on the comparison of benefits and cost of specialization. But the benefits and cost can't be calculated in money, which is partly depend on the farmers' subjective perception, hence, it is in vain to calculate them. In general, the farmers' professional decision-making is the results of a comprehensive survey of their own factors and related external factors. These factors, including characteristics of householder, family characteristics, product and environmental characteristics.

\subsection{Characteristics of rural householder}

In the rural household economy, householder often plays a key role in decision-making. Specifically:

Age. Age contains multiple meanings. First, the older householder is, the richer experience accumulated, more sensitive judgment, more ability to control risk, and might choose high efficiency specialization in agriculture or non-agricultural labor. Second, the older rural householder is prone to conservative ideas and limited to his own ability and energy. He tends to pure agricultural production. Third, he's old enough to form 
stronger risk aversion, and tends to select a variety of operating in the agricultural business process. Therefore, hypothesis 1 is proposed: Age of rural householder may affect farmers' specialized production but can not determine priori the direction of influence.

Educational level. The higher education level of householder is, his ideas is relatively flexible, more adept at operating and seizing opportunities, often engages in a high rate of return on investment in agricultural project, and specialized, large-scale operation. Accordingly to this, hypothesis 2 is proposed: the education level of rural householder has a positive impact on farmers' specialized production.

Whether accepting agricultural training or not. Specialized production can help farmers increase labor productivity, gain higher yields, and it often require producers to have a certain expertise and skills. Therefore, farmers received agricultural training are generally prefer to specialization. Thus, hypothesis 3 is proposed: whether rural householder accept agricultural training or not has a positive impact on farmers specialized production.

Risk attitude. Farmers specialization is actually the result of weighing the benefits and risks. Farmers raise labor productivity and gain specialization benefits through specialization, but also face a lot of risks due to the increase in market transactions and investment on specific asset. Therefore, risk attitudes often play a key role. Farmers tend to bear high degree of risk to gain specialization benefits, According to this, hypothesis 4 is proposed: the risk attitude of rural householder has a positive impact on farmers' specialized production.

\subsection{Characteristics of farmers' family and operation}

Characteristics of farmers' family and operation contain factors such as population and arable land area of farmers' family. Related to their limited resource endowments, the farmers with more population bear greater pressure to survive. Hence, they can't only rely on agriculture and have to turn to a variety of business or opportunities outside agriculture. Farmers' specialized production is closely related to the scale of arable land. Farmers with more arable land have a better chance to specialize in planting or breeding. Therefore, hypothesis 5 and 6 are proposed: The size of family population and arable land have negative and positive influence on farmers' specialized production respectively.

\subsection{Characteristics of agricultural products}

Different types of agricultural production farmers engaged in make a significant differences in the impact on farmers' specialization. Different types of agricultural products are very different in many respects, such as physical properties, elasticity of supply and demand, production efficiency, production and marketing requirements, etc. In general, farmers should invest more specific assets, labor or time into agricultural products that have the higher economic efficiency, such as vegetables, fruits, livestock and poultry, etc. Because these products are fresh and perishable, and their production process is relatively complex, the price fluctuates frequently, generally should be produced specially. Relatively. Thus, hypothesis 7 is proposed: Among all kinds of products, livestock and poultry may be the most appropriate specialized production, and then followed by fruits, Melons \&Vegetables, economic crops and grain crops.

\subsection{Characteristics of operating environment}

Farmers operating environment contains many things, such as the natural environment, political, legal, economic and social environment. If considering these factors: the difficulty of product sales, region, distance to the town, ratio of village migrant staff and policy support or not, the following assumptions may be proposed.

Hypothesis 8: The easier farmers sell agricultural products, the more inclination farmers have to choose specialized production.

Hypothesis 9: Regional variables can affect farmers specialized production, but the impact point is not clear.

Hypothesis 10: The distance to the town may have a positive impact on farmers specialized production.

Hypothesis 11: The number of staff village migrant has a negative impact on farmers specialized production.

Hypothesis 12: The policy support has a positive impact on farmers specialized production.

\section{The Empirical Analysis}

\subsection{Data sources}

In the summer in 2009, 100 students from rural areas were organized to investigate the farmers of the Villages where they live. Although we can't utilize rigorous and scientific sampling method to select samples, the study is still in strict accordance with the general investigation 
procedures. The survey covered basic information of the village, famer family, characteristics of rural householder and the environment of agricultural production and operation. After the investigation, a total of 1240 questionnaires were withdrew. According to the needs of the research, 358 questionnaires missing critical data were excluded and remained 882 valid questionnaires. The effective rate of the questionnaires was $85.2 \%$. The sample involved 882 farmers from 82 counties (cities) of 17 provinces (municipalities, autonomous regions).

According to the proximity of characteristics of agricultural products, they are divided into five categories in the paper: grain crops, economic crops, vegetables, fruits, and breeding. The distribution of these types of agricultural products is shown as follow: grain crops $54.4 \%$, economic crops $17 \%$, vegetables $11.9 \%$, fruits $7.4 \%$ and breeding $9.3 \%$.In the line with the specialization production standards described in the paper, namely the farmers' main product commercialization rate of more than $80 \%$ (among which the grain is involved 60\%), and its revenue accounts for more than $60 \%$ in the proportion of total household income, there are 348 professional farmers in the 882 survey farmers, accounting for $39.5 \%$; 534 general farmers, accounting for $60.5 \%$.

Table 1

Description of Model Variables

\begin{tabular}{|c|c|c|c|c|c|}
\hline Name of variable & $\begin{array}{l}\text { Variable } \\
\text { symbol }\end{array}$ & Unit or assignment & Mean & $\begin{array}{l}\text { Standard } \\
\text { deviation }\end{array}$ & $\begin{array}{l}\text { Expected } \\
\text { impact }^{(2)}\end{array}$ \\
\hline Explained variable: & $\mathbf{Y}$ & $\mathrm{Yes}=1 ; \mathrm{No}=0$ & & & \\
\hline Whether specialized or not & & & & & \\
\hline Explanatory variables: & CRH & & & & \\
\hline Characteristics of rural householder & & & & & \\
\hline Age & $\mathrm{X} 1$ & Years old & 44.39 & 8.92 & $+/-$ \\
\hline Educational degree & $\mathrm{X} 2$ & $\begin{array}{l}\text { Below primary =1;Primary =2; } \\
\text { Middle school =3; High school =4 } \\
\text { Above high school =5 }\end{array}$ & 2.91 & 0.90 & - \\
\hline Agricultural training & $\mathrm{X} 3$ & $\begin{array}{l}\text { Received }=1 ; \\
\text { Non-received }=0\end{array}$ & 0.19 & 0.39 & + \\
\hline Attitude toward risks & $\mathrm{X} 4$ & $\begin{array}{l}\text { Averse }=1 ; \text { More averse }=2 ; \\
\text { Moderate }=3 ; \\
\text { More preferable }=4 ; \text { Preferable }=5\end{array}$ & 3.09 & 1.26 & + \\
\hline $\begin{array}{l}\text { Characteristics of farmers' family } \\
\text { and operation }\end{array}$ & CFFO & & & & \\
\hline Resident population & $\mathrm{X} 5$ & Number(people) & 3.86 & 0.86 & - \\
\hline Arable land & X6 & acre & 19.17 & 32.22 & + \\
\hline Agricultural product type ${ }^{(1)}$ & APT & & & & \\
\hline Economic crops & $\mathrm{X} 7$ & Economic crops $=1 ;$ Others $=0$ & 0.17 & 0.38 & + \\
\hline Melons \&Vegetables & $\mathrm{X} 8$ & Vegetables $=1 ;$ others $=0$ & 0.12 & 0.32 & + \\
\hline Fruit & X9 & Fruit $=1 ;$ others $=0$ & 0.07 & 0.26 & + \\
\hline Breeding & $\mathrm{X} 10$ & Breeding $=1$; others $=0$ & 0.09 & 0.29 & + \\
\hline $\begin{array}{l}\text { Characteristics of farmers' } \\
\text { operating environment }\end{array}$ & CFOE & & & & \\
\hline Sales difficulty & $\mathrm{X} 11$ & yes $=1 ;$ no $=0$ & 0.21 & 0.41 & - \\
\hline Area & $\mathrm{X} 12$ & $\begin{array}{l}1=\text { the western } ; 2=\text { midland; } \\
3=\text { the eastern }\end{array}$ & 1.70 & 0.70 & $+/-$ \\
\hline Distance to town & $\mathrm{X} 13$ & $\mathrm{~km}$ & 4.69 & 5.13 & + \\
\hline The proportion of migrant workers & $\mathrm{X} 14$ & $\%$ & 23.75 & 16.43 & - \\
\hline Policy support & $\mathrm{X} 15$ & yes $=1 ;$ no $=0$ & 0.52 & 0.50 & + \\
\hline
\end{tabular}

Note:(1)the comparison is based on the grain ; (2) "+" indicates a positive effect, "-" indicates a negative effect, "+/-" indicates the impact point is not clear. 


\subsection{Variable design and model}

\subsubsection{Variable design}

Based on assumptions mentioned above, whether farmers specialized or not is influenced by factors as follows: (1) Characteristics of rural householder (CRH), specifically including age of rural householder (X1), education degree (X2), whether accepting agricultural skill training or not (X3), risk attitude (X4); (2) Characteristics of farmers' family and operation (CFFO),
$\mathrm{Y}_{\mathrm{i}}=\mathrm{F}\left(\mathrm{CRH}_{\mathrm{i}}, \mathrm{CFFO}_{\mathrm{I}}, \mathrm{APT}_{\mathrm{i}}, \mathrm{CFOE}_{\mathrm{i}}\right)+\mathrm{e}_{\mathrm{i}}$

$Y_{i}$ stands for whether the ith farmers choose specialization, $e_{i}$ is a random disturbance term. Every variable name, assignment statistics in the model and expected impact of each independent variable on the dependent variable are given in Table 1.

\subsubsection{Econometric model and method}

Farmers specialized production decision is a binary choice econometric model, so we can easily conceive of

Table3. The Logistic regression results of the specialized production influencing factors of farmers

\begin{tabular}{|c|c|c|c|c|c|c|c|c|}
\hline Explanatory variables & & B & S.E. & Wald & df & Sig. & $\operatorname{Exp}(\mathbf{B})$ & $\boldsymbol{\beta}$ \\
\hline \multicolumn{9}{|l|}{ Characteristics of rural householder } \\
\hline Age & & 0.009 & 0.010 & 0.782 & 1 & 0.376 & 1.009 & 0.000 \\
\hline Educational level & & $-0.323 * * *$ & 0.098 & 10.937 & 1 & 0.001 & 0.724 & -0.017 \\
\hline Agricultural training & & $0.520 * *$ & 0.225 & 5.367 & 1 & 0.021 & 1.682 & 0.065 \\
\hline Attitude toward risks & & $0.132 * *$ & 0.066 & 3.970 & 1 & 0.046 & 1.142 & 0.005 \\
\hline \multicolumn{9}{|c|}{$\begin{array}{l}\text { Characteristics of farmers' family and } \\
\text { operation }\end{array}$} \\
\hline Resident population & & $-0.290 * * *$ & 0.100 & 8.402 & 1 & 0.004 & 0.748 & -0.016 \\
\hline Arable land & & $0.025^{* * *}$ & 0.005 & 29.900 & 1 & 0.000 & 1.025 & 0.000 \\
\hline \multicolumn{9}{|l|}{ Agricultural product type } \\
\hline Economic crops & & $1.107 * * *$ & 0.236 & 22.038 & 1 & 0.000 & 3.024 & 0.144 \\
\hline Melons \&Vegetables & & $1.998 * * *$ & 0.256 & 61.035 & 1 & 0.000 & 7.373 & 0.282 \\
\hline Fruit & & $1.998 * * *$ & 0.311 & 41.357 & 1 & 0.000 & 7.373 & 0.343 \\
\hline Breeding & & $2.533 * * *$ & 0.289 & 77.103 & 1 & 0.000 & 12.596 & 0.404 \\
\hline $\begin{array}{l}\text { Characteristics of farmers' } \\
\text { environment }\end{array}$ & operating & & & & & & & \\
\hline Sales difficulty & & -0.122 & 0.208 & 0.342 & 1 & 0.558 & 0.885 & -0.014 \\
\hline Area & & 0.053 & 0.121 & 0.192 & 1 & 0.661 & 1.055 & 0.004 \\
\hline Distance to town & & $0.036^{*}$ & 0.019 & 3.723 & 1 & 0.054 & 1.037 & 0.000 \\
\hline The proportion of migrant workers & & $-0.018 * * *$ & 0.006 & 9.956 & 1 & 0.002 & 0.982 & 0.000 \\
\hline Policy support & & -0.027 & 0.168 & 0.025 & 1 & 0.874 & 0.974 & -0.003 \\
\hline Constant term & & -0.444 & 0.760 & 0.341 & 1 & 0.559 & 0.641 & -0.186 \\
\hline \multicolumn{9}{|l|}{ Overall test statistic of model } \\
\hline Forecast accuracy & & $76.3 \%$ & & \multicolumn{3}{|c|}{ Chi-square test value } & \multicolumn{2}{|l|}{285.018} \\
\hline -2 Log likelihood values & & 898.173 & & \multicolumn{3}{|c|}{ Cox \& Snell } & \multicolumn{2}{|l|}{0.276} \\
\hline Nagelkerke' R2 & & $0 . .374$ & & & & & & \\
\hline
\end{tabular}

Note: “*”, “**” and “***” indicates the statistical test reached 10\%, 5\% and 1\% significance level respectively. including family resident population (X5) and arable land area (X6); (3) Agricultural product trait (APT), which was reflect by type of product (X7); (4) Characteristics of farmers' operating environment (CFOE), including difficulty of products sale(X11), area(X12), distance to the town (X13), village migrant workers ratio (X14), whether supported by policy(X15). The main model can be expressed as the following function: the logistic regression model. Specific explanatory variable is whether farmers are specialization, the explanatory variables are the above various variables, mainly using the maximum likelihood method to estimate regression parameters. Besides, due to many explanatory variables in the model, it is necessary to test whether multicollinearity exists among the explanatory variables. It is found by the simple Pearson correlation test that several explanatory variables are significant in 
the $1 \%$ level, such as age and educational degree (correlation coefficient is -0.209), age and resident population (+0.155), educational degree and skill training (+0.104), skill training and arable land area $(+0.356)$, and region $(+0.182)$. But because all the relationship is very small, further research can not rule out any explanatory variable.

\subsubsection{The analysis of regression results}

A regression for Logistic model is made in SPSS13.0 through directly access method, and all the variables are introduced into the model once .The regression results are shown in Table 3.From the estimated results, the chi-square value is 272.109 , the $\mathrm{P}$ value $(\mathrm{Sig})<0.001$ and is very significant, and the prediction accuracy rate reaches $76.8 \%$, that is, the goodness of fit of the model is good. Among them, the standardized regression coefficient $\boldsymbol{\beta}$ eliminate the argument dimensionless impact of regression, which can be used to compare the relative roles of the explanatory variables. In general, the greater the variables is, the greater relative role is.

In terms of Characteristics of farmers' family and operation, the resident population and the arable land of farmers have a significant impact on specialized production. Resident population is significant at level of $1 \%$ and the coefficient is negative, which is consistent with the assumption. In the case of other conditions remain unchanged, families with more resident population have less willing to farmers specialization and if families resident population increase by 1 , the ratio of farmers specialization behavior dropped to $74.8 \%$. Arable land is significant at level of $1 \%$ and the coefficient is positive, which is consistent with the assumption. When the acres of arable land increase 1, the farmers specialized behavior expands 0.025 times. In the case of other conditions remain unchanged, the larger the farmers cultivated area is, the more willingness inclined to specialization.

In terms of the product characteristics, the type of product has a significant impact on the farmer specialized production. All types of products are significant at the level of $1 \%$ and the coefficient symbols are consistent with the assumption. Since the dummy variable of the product type is based on the comparison model of grain crops, the positive coefficient testifies that the grain corps have no superiority significant impact on farmers specialized production. That is, compared with other products, the farmers often tend to non-specialized. Further analysis from the estimated standardized regression coefficient $\beta$ 's value point, the extent of the product type affect farmers specialization is arranged in order from high to low as follows: breeding (0.404), fruits (0.343), melons \&vegetables (0.282) and economic crops (0.144). A conclusion can be made that farmers engaged in breeding, fruits, vegetables production have a higher willingness of specialization than those in the production of grain crops and economic crops.

In terms of Characteristics of farmers' operating environment, the distance to town and ratio of migrant staff have a significant affect on farmers specialization production, but the difficulty of product sales, region and the impact of policy support is not significant. The distance to town is significant at level of $10 \%$ and the coefficient is positive, which is consistent with the assumption. In the case of other conditions remain unchanged, those farmers are far away from town are inclined to specialization production. In addition, the distance to town increase per $1 \mathrm{Km}$, the ratio of farmers specialization expands 0.037 times. The ratio of migrant staff in the village is significant at the $1 \%$ level and the coefficient is negative, which is in line with expectations. In the case of other conditions remain unchanged, the higher the proportion of migrant staff is, the stronger the willingness of non-agricultural labor the farmers have, under the influence of the herd mentality. Combined with low speed of current agricultural land transfer, the willingness of farmers specialization production is weak relatively. Further more, if the proportion of migrant farmers increases $1 \%$, the ratio of specialization behavior is just $98.2 \%$ of the original. Although the difficulty of product sale has no obvious impact on the farmers specialization production, its symbol is negative, consistent with the expectations The more difficult in product sale, the more reluctant to specialization farmers are. Regional variables has no obvious impact on specialization production, inconsistent with expectations. Two reasons may be attached to it: First, although the non-agricultural employment opportunities in developed eastern regions, the range of agricultural products markets is larger and transportation and circulation is much easier, which is more suitable for the professional management of fresh 
agricultural.

From the estimated results of standardized regression coefficient $\beta$ value, the impact of various factors farmers specialized decision descending order: product type, whether householder accepting the agricultural skills training or not, education level of householder, family resident population, risk attitude, the distance to town ,ratio of migrant staff migrant workers and arable area. In the product type, the influence degree from great to small in turn for breeding, fruit, melons \&vegetables and economic crops.

\section{Conclusions and Recommendations}

It is a necessity for farmers specialized production to increase the agricultural productivity of labor in China, promote farmers sustained increasing, and realize the modernization of agriculture. The choice of farmers' specialization is a result of weighing specialization income and cost. Only when the specialized net income weighs over the net income of non-specialized, farmers would choose specialization. It is showed by empirical analysis with the data of 882 surveyed farmers that farmers specialized production is significantly influenced by collaborative effect of multiple factors which are education level of householder, whether householder receive agricultural skill training or net, risk attitude of householder, family size, arable area, product type, migrant workers ratio, the distance to town and other factors. According to the results of the empirical research, we've made following recommendations in order to promote the specialized production of farmers in China.

(1)Adjust the structure of rural education actively and attach importance to strengthen the vocational and technical education in rural areas. Utilize various types of training methods consorting to local conditions, closely centering the restructuring of agricultural production farmers' particular production projects and operating mode. Guide young adults to engage in agricultural production and management, training farmers to learn skills of specialization and large-scale production. Improve the level of farmers' specialization effectively.

(2)Speed up the transfer of rural surplus labor force and the urbanization procession. Encourage farmers to make agricultural land into the ordered circulation and moderate scale operation. Strengthen vocational skills training for rural migrant workers in order to improve the procession of urbanization. On this basis, encourage farmers vigorously to transfer the agricultural land use right, and to create the conditions for large-scale and professional management of the farmers.

(3)Continue to implement strengthened and preferential agricultural policy, gradually increase the degree of organization of farmers. Through the implementation of the policy, it is benefit for further reducing farmers' burden and improving farmers' welfare; Improve the extend of organization of farmers by actively training of different kinds of rural economic organizations. As the recommendations above carried out, it is helpful to some extent to improve the risk-bearing capacity of farmers, thus benefiting the farmers engaging in specialized production.

(4)Strengthen rural infrastructure for the purpose of creating conditions for transfer of rural surplus labor and agricultural land, then for some farmers realizing specialization, scale operation.

\section{References}

FANG Hui zhen. "a summary of the study and discussion of rural specialized households" [J]. Chinese rural econom),(9) pp.37-40,1985

LUO Dan, Chen Jie. "farmers specialization : agricultural industrialization process, the most important issue"[J].Journal of Northwest $A \& F$ University(Social Science Edition,(11) pp.38-41,2001

ZHOU Duan-ming,Cai Min."the reasons for the low degree of specialization of China Agricultural analysis and explore the way out" [J].Journal of Anhui Normal University (Humanities and Social Scienc),(2) pp.181-184, 2000 